\title{
Comparative study of conventional urosonography without contrast enhancement and $x$-ray voiding cystourethrography for diagnosis of vesicoureteral reflux in children
}

\author{
Nadide Basak Gulleroglư ${ }^{1}$, Kaan Gulleroglu*2, Esra Baskin ${ }^{2}$ \\ ${ }^{1}$ Ankara City Hospital Children's Hospital, Pediatric Radiology, Ankara, Turkey \\ ${ }^{2}$ Baskent University, Pediatric Nephrology, Ankara, Turkey
}

Received: November 30, 2020

Accepted: March 15, 2021

Online Published: March 30, 2021

DOI: $10.5430 / \mathrm{dcc} . \mathrm{v} 7 \mathrm{n} 4 \mathrm{p} 9$

URL: https://doi.org/10.5430/dcc.v7n4p9

\begin{abstract}
Background: Vesicoureteral reflux is the most common urinary congenital anomaly in children. Given the risk associated with radiation exposure there has been an increasing need for radiation-free method in the diagnosis and follow-up of the vesicoureteral reflux. The aim of our study is to compare conventional urosonography without contrast enhancement and $\mathrm{x}$-ray voiding cystourethrography.

Patients and Methods: Children with recurrent urinary tract infection with suspected vesicoureteral reflux were included to the study. Vesicoureteral reflux is demonstrated and graded by x-ray voiding cystourethrography. DMSA is used for the evaluation of renal scar. Conventional sonographic procedure was performed in all patients. Ureterovesical junction insertion angle was evaluated. The diameter and length of the ureterovesical junction were also measured.

Results: 268 children enrolled to the study. Vesicoureteral reflux was demonstrated in 62 children by x-ray voiding cystourethrography. Ureterovesical junction insertion angle measurement had a statistically significant relation for right and left vesicoureteral reflux presence (right: $r: .646, p: .01$ and left: $r: .446, p: .01$ ). Diagnosis sensitivity of vesicoureteral reflux with conventional ultrasonography is $95.10 \%$ and specificity is $81 \%$ (Youden's index $76.1 \%$ ) for the cutoff value of the ureterovesical junction insertion angle is 28.6 degrees. Positive predictive value is $87.2 \%$, negative predictive value is $94.73 \%$ and diagnostic accuracy is $86.29 \%$ with conventional ultrasonography.

Conclusions: Measurement of ureterovesical junction insertion angle, length and diameter by conventional urosonography is an easy accessible and cheap technique with high sensitivity and specificity for the diagnosis and followup of the vesicoureteral reflux without exposure to ionizing radiation.
\end{abstract}

Key Words: Vesicoureteral reflux, Conventional urosonography, X-ray voiding cystourethrography, Ureterovesical junction insertion angle

*Correspondence: Kaan Gulleroglu; Email: kaangulleroglu@yahoo.com; Address: Baskent University, Pediatric Nephrology, Ankara, Turkey. 


\section{INTRODUCTION}

Vesicoureteral reflux (VUR) is the most common urinary congenital anomaly in children. It predisposes children to urinary tract infection, renal scarring and chronic renal failure. X-ray voiding cystourethrography (VCUG) is routinely applied for the detection of vesicoureteral reflux. However this technique involves exposure to ionizing radiation. Given the risk associated with radiation exposure there has been an increasing need for radiation-free method in the diagnosis and follow-up of the vesicoureteral reflux.

In the past years many efforts were being made for the demonstration of VUR without radiation exposure. Reflux diagnosis with ultrasonography (US) was studied by recent studies. Indirect US methods such as ureteral and pelvicalyceal dilatation, pelvic and ureteral wall thickening, sign of dysplasia and direct US methods by using bladder catheterization and various substance were performed for this goal. Although the technical improvements, impossibility to exclude VUR if the urinary tract is completely normal, defects for visualizing all reflux grades and need for an US contrast agent and bladder catheterization were the limitations of reflux diagnosis with US. ${ }^{[1-3]}$ Determining more precise criterion for US will be helpful in decision making during follow-up of the patients with urinary tract infection.

The aim of our study is to compare conventional urosonography without sonographic contrast media enhancement and $\mathrm{x}$-ray voiding cystourethrography and to determine a criterion for increasing suspicion of VUR in US.

\section{Patients And methods}

Children with recurrent urinary tract infection with suspected vesicoureteral reflux were included to the study. Demographic and clinical data of the patients were recorded by patient' cards. All patients underwent urinary tract ultrasonography, $\mathrm{x}$-ray voiding cystourethrography and dimercaptosuccinic acid (DMSA) scan. Urinary tract ultrasonography was performed before VCUG and DMSA.

Conventional sonographic procedure was performed with a Toshiba Aplio 80 equipped with a 3.5 to $7.5 \mathrm{MHz}$ convex multiple frequency electronic transducers. In all patients urinary tract US was performed in supine position with suprapubic area exposed, including size, shape, presence of hydronephrosis, scars and parenchymal thickness and structure of the kidney and urinary tract. The bladder volume was measured in conventional ultrasound examination on the frozen ultrasound pictures (see Figure 1). Bladder capacity was calculated with Koff's formula (bladder volume $(\mathrm{ml})=[($ age $($ years $)+2] \times 30$ for each patient. Each ultrasound scan was done during morning period of the day. Patients were allowed for drinking water but avoid eating. Every patient went through bladder volume calculation for several times to catch the estimated optimal bladder capacity according to the age. When the bladder volume was enough for exam, the transducer was angled laterally and swept both left and right sides to check the bladder wall and margins. The ultrasound beam was projected as close to perpendicular to the bladder wall as possible. The ureteral orifices were determined by following ureteral traces in transverse plane and by the help of ureteric jets on both sides. The transducer was angled in oblique-sagittal plane; parallel to the distal ureteral trace. The ureterovesical junction is a straight elliptical tunnel shaped line through the bladder wall. Ureterovesical junction inserts an angle into the bladder trigone. This angle between bladder wall and the ureteral orifices on each side of the bladder in the oblique-sagittal plane was evaluated. The diameter of ureterovesical junction was also measured at the same plane as the ureterovesical junction insertion angle was measured in the oblique sagittal plane (see Figure 2).

VCUG was undertaken by using a digital screening unit (Siemens Luminos dRF Max). A transurethral catheterization was performed before the procedure using a $6 \mathrm{~F}$ or $8 \mathrm{~F}$ feeding tube in aseptic condition. The bladder was filled through the catheter by means of gravity with prewarmed at $37^{\circ} \mathrm{C}$ contrast medium. The estimated bladder capacity for patient's age was calculated by the formula $(\mathrm{ml}=(30 \times$ age) +30 ). Filling was checked with intermittent digital fluoroscopy. Vesicoureteral reflux is confirmed and graded according to the international classification.

DMSA is used for the evaluation of renal scar. All ultrasonographic data is compared with data derived from x-ray voiding cystourethrography and DMSA scan.

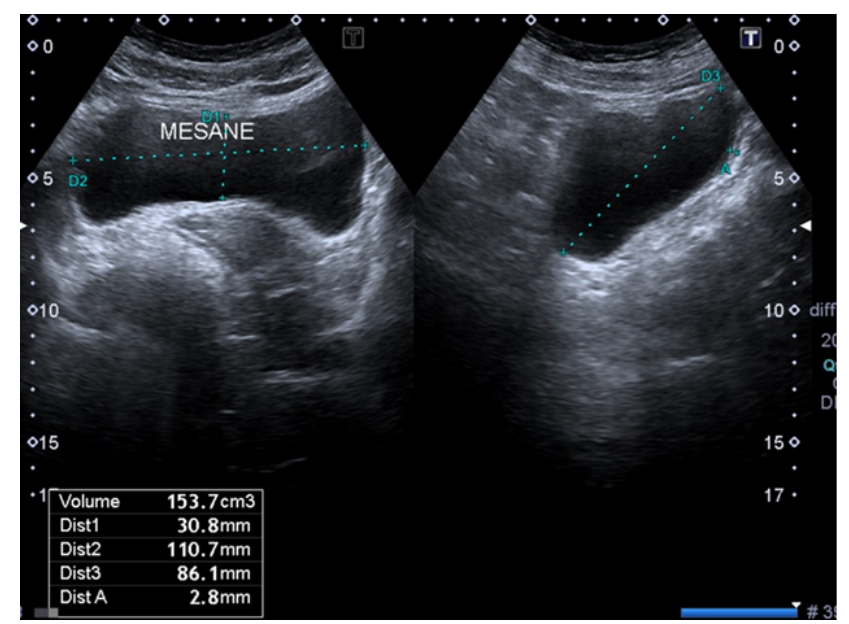

Figure 1. Bladder volume calculation and bladder wall thickness by conventional US 
Local ethical committee approval and voluntary informed consent were obtained.

Results were analyzed using SPSS-21 software for Windows ${ }^{\circledR}$ (Chicago, IL). Sensitivity, specificity, positive predictive value (PPV), negative predictive value (NPV) and Youden's index (YI) were calculated. The best cutoff value of the ureterovesical insertion junction angle was determined by using ROC curve and Youden's index. Youden's indexes of recent studies were also calculated for diagnostic performance comparison.

A $p$ value $<.05$ was considered to indicate statistical significance.
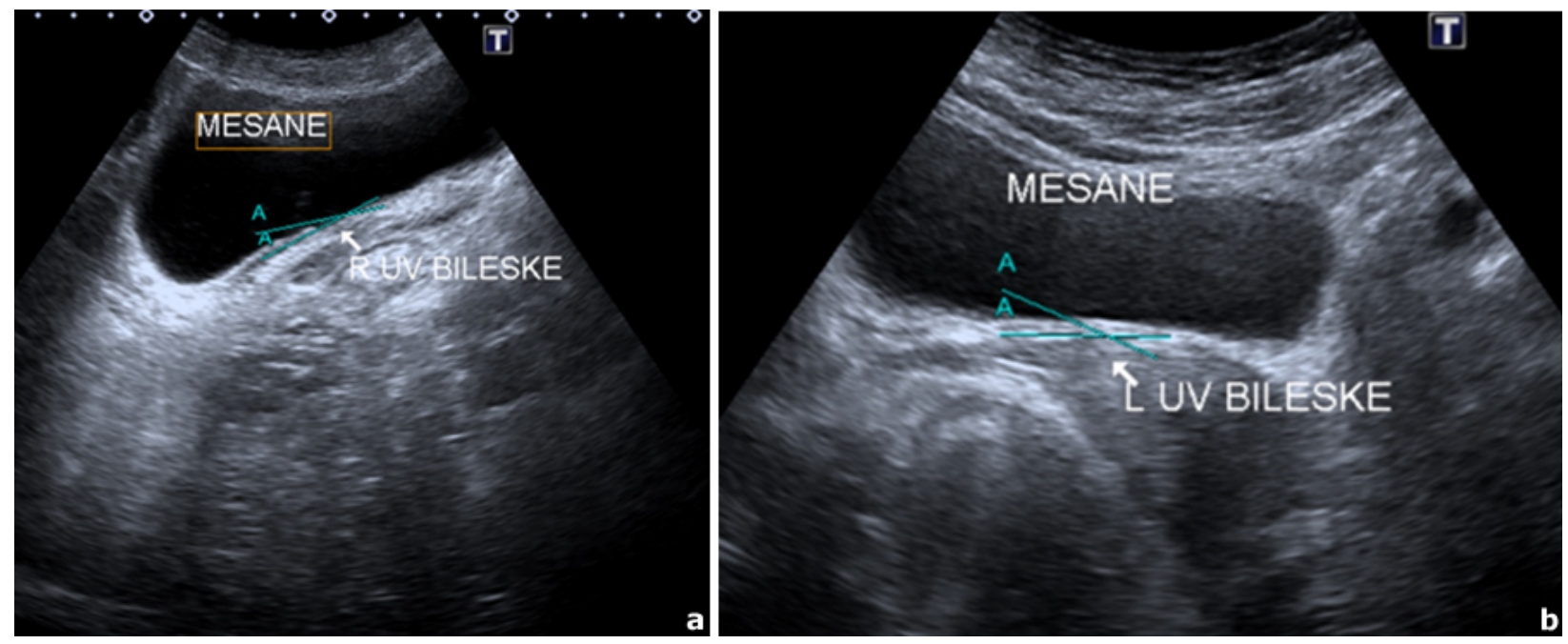

Figure 2. Measurement of the angles between vesical wall and the both ureterovesical junctions, in oblique-sagittal plane (a) Right UV junction, (b) Left UV junction

\section{RESUlts}

268 children (F/M: 179/89) with recurrent urinary tract infection with suspected vesicoureteral reflux were included to the cross-sectional study. These patients did not have any surgical procedure history before application. Vesicoureteral reflux was demonstrated in 62 children (F/M: 41/21) by $\mathrm{x}$ ray voiding cystourethrography. All patients had primary VUR. Mean age of the patients was $4.20 \pm 3.36$ years. The age of 23 patients with vesicoureteral reflux (37.09\%) was under 2 years old. Median height of the patients was 96.5 $\mathrm{cm}$ (min: 52 - max: 145). Mean serum creatinine value was $0.38 \pm 0.16 \mathrm{mg} / \mathrm{dl}$ and renal functions were in normal ranges in all patients.

Vesicoureteral reflux was confirmed in 84 of the 536 ureterovesical junction units. 22 patients had bilateral vesicoureteral reflux. 6 patients with bilateral vesicoureteral reflux were younger than 2 years old. High grade $\left(4^{\text {th }}\right.$ and $5^{\text {th }}$ degree) vesicoureteral reflux was $29.76 \%$ of all vesicoureteral reflux. High grade vesicoureteral reflux ratio under 2 years old was $39.13 \%$. Low grade reflux ratios under 2 years old were $21.73 \%$ for grade $1^{\text {st }}, 21.73 \%$ for grade $2^{\text {nd }}$ and $17.41 \%$ for grade $3^{\text {rd }}$ (see Tables 1-2).

Ureterovesical junction insertion angle measurement was statistically significant increased degree in vesicoureteral reflux

Published by Sciedu Press presence when compared with vesicoureteral reflux absence (see Table 2). We demonstrated that ureterovesical junction insertion angle measurement had a statistically significant relation for right and left vesicoureteral reflux presence (right: $r: .646, p: .01$ and left: $r: .446, p: .01)$.

Diameter of ureterovesical junction measurement was statistically significant wider in vesicoureteral reflux presence when compared with vesicoureteral reflux absence (see Table 3). Another statistically significant relation demonstrated between diameter of right ureteral orifice and vesicoureteral reflux presence ( $r: .309, p: .05)$. Increase in the diameter of left ureterovesical junction detected, although any statistically significant relation between diameter of left ureterovesical junction and vesicoureteral reflux.

The measurement of ureterovesical junction insertion angle and diameter of ureterovesical junction with conventional ultrasonography, vesicoureteral reflux can be demonstrated ( $p$ $<.05)$. Diagnosis sensitivity of vesicoureteral reflux with conventional ultrasonography is $95.1 \%$ and diagnosis specificity of vesicoureteral reflux with conventional ultrasonography is $81 \%$ and Youden's index $76.1 \%$ for the cutoff value of the ureterovesical junction insertion angle is 28.6 degrees. Diagnosis sensitivity of low grade vesicoureteral reflux with conventional ultrasonography is $94.3 \%$ and diagnosis specificity 
of vesicoureteral reflux with conventional ultrasonography is $77.1 \%$ and Youden's index $71.4 \%$ for the cutoff value of the ureterovesical junction insertion angle is 28.6 degrees. Positive predictive value (PPV) is $87.2 \%$, negative predictive value is $94.73 \%$ and diagnostic accuracy is $86.29 \%$ with conventional ultrasonography when compared with VCUG considering the ureterovesical junction units (see Table 4).
All patients underwent DMSA scan. Renal scar was shown in $35(56.45 \%)$ patients by DMSA. Ultrasonography could demonstrate renal scar in $23(65.71 \%)$ of these patients. A statistically significant correlation cannot be demonstrated between renal scar in DMSA scan and measurements of ureterovesical junction insertion angle and diameter of ureterovesical junction.

Table 1. X-ray voiding cystourethrography results of the patients

\begin{tabular}{lll}
\hline Vesicoureteral reflux grade & Left Kidney (n / \%) & Right Kidney (n /\% ) \\
\hline None & $8(12.90 \%)$ & $32(51.60 \%)$ \\
1 & $18(29.00 \%)$ & $9(14.50 \%)$ \\
2 & $8(12.90 \%)$ & $6(9.70 \%)$ \\
3 & $12(19.40 \%)$ & $6(9.70 \%)$ \\
4 & $11(17.70 \%)$ & $4(6.50 \%)$ \\
5 & $5(8.10 \%)$ & $5(8.10 \%)$ \\
Total & $62(100.00 \%)$ & $62(100.00 \%)$ \\
\hline
\end{tabular}

Table 2. X-ray voiding cystourethrography results of the patients according to age

\begin{tabular}{lll}
\hline Vesicoureteral reflux grade & $<2$ years old $(\mathbf{n} / \%)$ & $>2$ years old $(\mathbf{n} / \%)$ \\
\hline 1 & $5(8.10 \%)$ & $11(17.74 \%)$ \\
2 & $5(8.10 \%)$ & $6(9.67 \%)$ \\
3 & $4(6.45 \%)$ & $12(19.35 \%)$ \\
4 & $6(9.67 \%)$ & $7(11.38 \%)$ \\
5 & $3(4.77 \%)$ & $3(4.77 \%)$ \\
Total & $23(37.09 \%)$ & $39(62.91 \%)$ \\
\hline
\end{tabular}

Table 3. Ultrasonographic findings of the ureterovesical junction units

\begin{tabular}{llll}
\hline & VUR presence & VUR absence & $\boldsymbol{p}$ \\
\hline Left UV junction insertion angle measurement $\left(^{\circ}\right)$ & $40.69 \pm 7.05$ & $22.23 \pm 4.57$ & .02 \\
Right UV junction insertion angle measurement $\left(^{\circ}\right)$ & $39.75 \pm 7.28$ & $23.94 \pm 4.45$ & .01 \\
Diameter of left UV junction measurement $(\mathrm{mm})$ & $4.33 \pm 2.10$ & $2.30 \pm 0.40$ & .005 \\
Diameter of right UV junction measurement $(\mathrm{mm})$ & $4.20 \pm 2.30$ & $2.51 \pm 0.91$ & .001 \\
\hline
\end{tabular}

Note. VUR: Vesicoureteral reflux; UV: Ureterovesical

Table 4. Diagnosis sensitivity and specificity of vesicoureteral reflux with conventional ultrasonography compared with VCUG considering the ureterovesical junction units

\begin{tabular}{|c|c|c|c|c|}
\hline & VCUG (+) & VCUG (-) & Total & \\
\hline $\mathrm{USG}(+)^{*}$ & 75 & 6 & 81 & Sensitivity $98.80 \%$ \\
\hline USG $(-)^{* *}$ & 11 & 32 & 43 & Specificity $81.00 \%$ \\
\hline \multirow[t]{2}{*}{ Total } & 86 & 38 & 124 & \\
\hline & PPV 87.20\% & NPV 94.73\% & & Accuracy $86.29 \%$ \\
\hline
\end{tabular}




\section{Discussion}

Vesicoureteral reflux is one of the most important causes of recurrent urinary tract infection and renal scarring. The prevalence of VUR varies from $1.3 \%$ of healthy children to $8 \%-50 \%$ of children with urinary tract infection. ${ }^{[4]} \mathrm{X}$-ray voiding cystourethrography is gold standard for diagnosis. Early diagnosis and intervention may help to prevent from renal scars. Adverse effects related to ionizing radiation and urethral catheterization limit extensive usage of this imaging technique. It is not always an accessible technique for all medical centers. A noninvasive, radiation free, cheap and available method will change the course of the disease.

In recent studies US was widely used for the diagnosis of VUR. Conventional US finding for suggestion of VUR were dilatation of pelvicalyces, ureters or collecting systems in these studies. ${ }^{[5]}$ Voiding urosonography was another method which was developed for the detection of VUR. Despite the elimination of adverse effects related to ionizing radiation, the limitations of the voiding urosonography were a requirement of catheterization and echocontrast media usage. ${ }^{[6-8]}$ In these studies, another evaluation method of VUR was visualization of Doppler signals (retrograde flow into the ureter) from the bladder to ureter during the course of bladder filling by using a color Doppler US. This procedure could be applied only patients aged $\geq 2$ years because it required compliance from the patients. ${ }^{[9,10]}$

The sensitivity of conventional US for detection of VUR was $40 \%$ with specificity $76 \%$ (5). The sensitivity of voiding urosonography for detecting VUR was demonstrated between $57 \%$ and $100 \%$ and specificity between $85 \%$ and $100 \% .^{[2]}$ Demonstration of VUR with retrograde flow into the ureter by Doppler US had sensitivity between $81.6 \%$ and $90 \%$ and specificity between $82.7 \%$ and $93 \% .{ }^{[9,10]}$ In our study we used conventional US with a new measurement procedure and we demonstrated that our sensitivity for detecting VUR without catheterization and echocontrast media usage was $95.1 \%$ and our specificity $81 \%$ for all degree of VUR and Youden's index $76.1 \%$ for the cutoff angle of 28.6 degrees or greater. Conventional ultrasonography findings (presence of hydronephrosis, scars and parenchymal thickness and structure of the kidney and urinary tract) can be helpful for suspicion of high grade vesicoureteral reflux but low grade vesicoureteral reflux cannot be demonstrated by these findings. Our technique has also a high sensitivity (94.3\%) and specificity (77.1\%) for low grade vesicoureteral reflux and it will be helpful for the suspicion of vesicoureteral reflux. We calculated Youden's indexes of recent studies for diagnostic performance comparison of our study.

Published by Sciedu Press
Youden's index of Mahant's study ${ }^{[5]}$ was $16 \%$, Asanuma's study ${ }^{[10]}$ was $64.3 \%$ and Koşar's study ${ }^{[9]}$ was $83 \%$. Youden's index of our study is relatively higher when compared with recent studies. This high index value demonstrates the efficacy of our technique. We also demonstrated that Youden's index of our study is also higher for low grade vesicoureteral reflux detection. In Asanuma study ${ }^{[10]}$ by visualization of Doppler signals (retrograde flow into the ureter), the cutoff angle was accepted 55 degrees or greater for detecting grade 3 to 5 grade with a lower sensitivity $(85.5 \%)$ than our study. Koşar et al. ${ }^{[9]}$ by using same visualization of Doppler signals (retrograde flow into the ureter) were that the sensitivity was $90 \%$ and specificity $93 \%$. Because the requirement of the patient's compliance this method could not be applied to patients under 2 years old. It is a handicap for clinical practice when considering the need of visualization of the urinary tract require mostly during earliest childhood. 23 of our patients with vesicoureteral reflux were under 2 years of age. Our study does not required patient's compliance for angle measurement. We did not use retrograde flow into the ureter by color doppler US. Appropriate bladder volume is enough for ureterovesical junction insertion angle detection. Bladder volume measurement could be done easily in any age of the patients.

The structure of the study was a cross-sectional design. US scans were performed before VCUG in all patients with recurrent urinary tract infection. Study had some limitations related to the design. All patients had primary VUR and also they had no surgical interventions at the time of the investigations. Similar angular calculations with US were not performed during long-term follow-up. Ureterovesical junction insertion angle measurements in our study did not refer the VUR classification. For these reasons this study could not respond to questions about angular changes related with grow-up of children with VUR, related to surgical procedures, or about the grade of VUR. This study could not also compare differences between primary and secondary VUR. Future studies in this area can respond to these questions. Although these limitations we demonstrated that increased angles were suspicious about VUR existence in the patients with urinary tract infection. It is a more precise criterion in US for increasing suspicion of VUR.

According to our knowledge, our study is the first study on the demonstration of VUR with this technique. Measurement of ureterovesical junction insertion angle and diameter of ureterovesical junction by conventional ultrasonography is an easy accessible and cheap technique for all medical centers. It is a non-invasive and radiation free technique and also it has reasonably high sensitivity, specificity and 
good Youden's index. It can be used for the diagnosis and CONFLICTS OF INTEREST DiSCLOSURE

followup of the vesicoureteral reflux with high sensitivity The authors declare they have no conflicts of interest. and specificity.

\section{REFERENCES}

[1] Darge K. Diagnosis of vesicouretheral reflux with ultrasonography. Pediatric Nephrology. 2002; 17: 52-60. PMid:11793136. https: //doi.org/10.1007/s004670200010

[2] Snow BW, Taylor MB. Non-invasive vesicoureteral reflux imaging. Pediatric Urology. 2010; 6: 543-549. PMid:20488755. https : //doi.org/10.1016/j.jpurol.2010.02.211

[3] Bates DG, Riccabona M. Vesicoureteral reflux. In: Caffey's Pediatric Diagnostic Imaging 12th edition. Ed: Coley BD. Elsevier Saunders: Philadelphia; 2013. 1253-1261 p.

[4] Mattoo TK, Mathews R, Gupta IR. Vesicoureteral reflux and renal scarring in children. In: Pediatric Nephrology, 7th edition. Eds: Avner ED, Harmon WE, Niaudet P, Yoshikawa N, Emma F, Goldstein SL. Springer-Verlag: Berlin Heidelberg; 2016. 1716-1748 p. https ://doi.org/10.1007/978-3-662-43596-0_50

[5] Mahant S, Friedman J, MacArthur C. Renal ultrasound findings and vesicoureteral reflux in children hospitalized with urinary tract infection. Arch Dis Child. 2002; 86: 419-421. PMid:12023172. https://doi.org/10.1136/adc.86.6.419

[6] Castagnetti M, Cimador M, Tudisco V, et al. Discrepancy between power-Doppler voiding urosonography and voiding cystoureterhrog- raphy is not relevant for the management of primary vesicoureteric reflux. J Pediatric Surgery. 2006; 41: 1285-1289. PMid:16818064. https : //doi.org/10.1016/j.jpedsurg. 2006.03.008

[7] Valentini AL, De Gaetano AM, Minordi LM, et al. Contrast-enhanced voiding US for grading of reflux in adult patients prior to antireflux ureteral implantation. Radiology. 2004; 233(1): 35-39. PMid:15317946. https://doi.org/10.1148/radiol. 2331031 803

[8] Valentini AL, Salvaggio E, Manzoni C, et al. Contrastenhanced gray-scale and color Doppler voiding urosonography versus voiding cystourethrography in the diagnosis and grading of vesicoureteral reflux. J Clinical Ultrasound. 2001; 29(2): 65-71. https://doi.org/10.1002/1097-0096(200102 ) $29: 2<65::$ AID-JCU1000>3.0.CO;2-I

[9] Koşar A, Yeşildağ A, Oyar O, et al. Detection of vesico-ureteric reflux in children by colour-flow Doppler ultrasonography. BJU International. 2003; 91: 856-859. PMid:12780848. https://doi.or g/10.1046/j.1464-410X. 2003.04223.x

[10] Asanuma H, Matsui Z, Hiroyuki S, et al. Color Doppler ultrasound evaluation of ureteral jet angle to detect vesicoureteral reflux in children. J Urology. 2016; 1877-1882. PMid:26804751. https://doi.org/10.1016/j.juro.2016.01.055 